\title{
Knockdown of ET-1 Gene Can Inhibit the Proliferation, Invasion of Human Prostate Cancer Cell \\ J Liu, X Liu
}

\begin{abstract}
Prostate cancer is the sixth most common fatal cancer and the second most frequently diagnosed cancer of male worldwide. Endothelin-1 (ET-1), generated by the prostate epithelia, plays a vital role in the genesis and the development, of prostate cancer. ET-1 has been previously reported in prostate and other organs. However, ET-1 expression in Prostate cancer cell lines has not been described. Therefore, we have used Western Blot to demonstrate the expression level of ET-1 in PC3 cell line. The results suggest the expression of ET-1 is significantly high expressed in PC3 cell line. Moreover, knockdown of ET-1 gene with siRNA can effectively repress the cell proliferation and the cell cycle was blocked in G1/G2 phase. Knockdown of ET-1 gene can affect cell invasion, which is confirmed by cell invasion and migration related genes using west blot ( $\beta$-catenin, E-cadherin, RhoC and RhoA). The results of this study can describe the characterization of ET-1in the development of primary human Prostate cancer, which can lead to a better understanding of the changes occurring at the molecular level during the development and progression of cancer.
\end{abstract}

Keywords: Cell cycle, cell proliferation, human, prostate cancer; western blot

From: Department of Urology, Renmin Hospital of Wuhan University, Wuhan 430060, Hubei Province, China.

Correspondence: Dr X Liu, Department of Urology, Renmin Hospital of Wuhan University No. 238 Jiefang Road, Wuchang District,Wuhan, Hubei, 430060, China E-mail: xiuhengliu@sina.com. 


\section{INTRODUCTION}

Low rates of cell proliferation coupled with diminished rates of cell death are the outstanding characteristics of prostate cancer (1). The patterns mentioned above make cytotoxic chemotherapeutic agents do not work to prostate cancer. In 2016, 180,890 men are expected to be diagnosed as prostate cancerand 26, 120 will die of metastatic disease (2). Most of localized prostate cancers can be controlled using surgery and/or radiation treatments. However, metastatic disease is still a type of lethal disease with no curative options. Furthermore, prostate cancer can be highly lethal or slow and indolent, which indicate it is a heterogeneous disease, a 10-year estimated survival of $17 \%$ (2). The results mentioned also make a reflection of underlying genomic diversity. Large-scale cancer genome projects of glioblastoma, lung, colon, pancreas, and breast cancers have accomplished, which give us more information about the molecular classification of cancers and the therapeutic targets (3-5). However, there still have difficulties for large-scale multicenter genomics projects of prostate cancer,including the relatively small tumor size and admixture with stroma. Previous studies have analyzed transcriptomes and copynumber variations (CNVs) in prostate cancer, but the disadvantage of most of those studies focus on sample collection(rarely from the same samples) and experimental platforms (lower resolution platforms) (6-8). Numerous transcriptome studies have defined the features of prostate cancer; however, unlike breast cancer (9-10), these analyses have no more specific detailed classification of prostate cancer (11-12). For now, the varieties of affordable and efficient techniques have been appliedfor profiling tumors, which can make us to better understand the potential molecular mechanisms of prostate cancer. For example, many clinical trials have already to perform the examination whether molecularly targeted therapies can improve outcomes (13). 
The potent vasoconstrictor peptide endothelin-1 (ET-1) was first isolated from the culture media of porcine endothelial cells in 1988 (14). It is one of a family of multifunctional peptides (ET-1, 2 and 3) that are closely related to the sarafotoxins derived from the venom of the burrowing asp. ET-1, like its relatives ET-2 and ET-3, is a 21-amino-acid peptide, which is composed by a single alpha-helix and two disulfide bridges. Three endogenous endothelins are encoded by different genes. The primary translation product of the ET-1 gene is the 212-aminoacid prepro-ET-1, which is then cleaved to form the 38-amino-acid big-ET-1. Biological actives of ET-1 are generated by endothelin-converting-enzyme (ECE) (15). ET-1 has a relatively short half-life: seven minutes in circulation (16). Of these isoforms, ET-1 has been the most extensively studied to date, and has been implicated in cancer. Two mechanisms have been reported for inactivation of endothelin: ET-в receptor-mediated uptake followed by lysosomal degradation (17-18) and catabolism by extracellular neutral endopeptidase (NEP) (19). Endothelin production is stimulated by a variety of cytokines and growth factors, including IL-1 $\beta$ (20), TNF- $\alpha$ (21), TGF- $\beta$ (22), platelet derived growth factor (23), vasopressin (24), prostate specific antigen (25) and low-density lipoprotein (26). Local low oxygen tension and shear stress on vessels walls also increase ET-1 production (27-28). ET-1has been detected in the progression of prostate cancer (29-30). Moreover, patients with metastatic prostate cancer have high levels of plasma ET-1 compared with patients with organ-confined cancer (31). Activation of the endothelin receptor $\mathrm{A}\left(\mathrm{ET}_{\mathrm{A}}\right)$ can stimulate a survival pathway, whereas activation of the endothelin receptor $\mathrm{B}\left(\mathrm{ET}_{\mathrm{B}}\right)$ can clear the circulating $\mathrm{ET}-1$ and stimulate the apoptosis. In prostate cancer, the expression levels of the endothelin receptors, $\mathrm{ET}_{\mathrm{A}}$ and $\mathrm{ET}_{\mathrm{B}}$, is significantly different compared to the pattern in normal prostatic tissues (32). The $\mathrm{ET}_{\mathrm{B}}$, has a much lower expression level in prostate cancer cells, which can be attributed to the frequent 
hypermethylation of $\mathrm{ET}_{\mathrm{B}}$ gene (33). In studies of endothelial and stromal cell populations, ET-1 can inhibit apoptosis induced by a cytotoxic agent (34). Based on the evidences mentioned above, it is our hypothesis that ET-1 act as an important role inprostate cancer. Therefore, we investigated the effects of ET-1 knockdown treatment in PC-3 cell line. This study would help to understand the characterization of ET-1 in the development of in primary human prostate cancer.

\section{SUBJECTS AND METHODS}

\section{Cell treatment}

PC-3 cell line, DU145 cell line and LBCaP cell line were purchased from ATCC (Virginia, USA), and maintained in RPMI 1640 with 10\% (v/v) FBS (Invitrogen, Carlsbad, CA). Cell lines were maintained in a humidified chamber at $5 \% \mathrm{CO}_{2}$, at $37^{\circ} \mathrm{C}$. Double-stranded siRNAs (dsRNA) targeting the ET-1 gene (NM_001168319) and complementary dsRNA were synthesized (ReiBo Biotech, China). The sequence of dsRNA for human ET-1 mRNA was 5'-ggg ucu aca uca acu auu a.dTdT-3' and 3'-dTdTcce aga ugu agu uga uaa u-5'. The sequence of the control siRNA from a scramble sequence was 5'-uuc ucc gaa cgu guc acg u.dTdT-3' and 3'-dTdT aag agg cuu gca cagugc a-5'. Cells were seeded in 6-well plates with $5 \times 10^{5}$ cells per well with DMEM (10\% FBS without penicillin and streptomycin overnight). Transfection was carried out with OPTIMEM serum-free medium and Lipofectamine 2000 reagent (final siRNA concentration: 50 or $100 \mathrm{nM})$.

\section{Cell proliferation assays}

A cell proliferation assay was conducted with MTT kit (Sigma) according to the manufacturer's instruction. For the colony formation assay, 500 cells were placed into each well of 6-well plate and maintained in media containing $10 \%$ FBS for 2 weeks. Colonies were fixed with methanol 
and stained with $0.1 \%$ crystal violet (Sigma) in PBS for 15 minutes. Colony formation was judged by counting the number of stained colonies in 3 randomly selected fields using inverter microscope. Triplicate wells were measured in each treatment group.

\section{Cell cycle analysis}

Flow cytometric analyses were performed to estimate cell cycle distribution. After 6, 12, 24 and 48h from transfection, cells were harvested by trypsinization and fixed with $70 \%$ ethanol. Cells were stained for total DNA content with a solution containing $20 \mu \mathrm{g} / \mathrm{ml}$ propidium iodide. Cell cycle distribution was then analyzed using a FACS calibur flow cytometer (BD Biosciences).

\section{Invasion assay}

Cell invasion was analyzed by using Cultrex 24-well BME Cell Invasion Assay (Trevigen Inc., Gaithersburg, MD, USA) according to standard procedures. Briefly, $10^{3}$ PC3-1 cells were seeded in $100 \mu 1$ serum-free media into the upper wells (coated with Matrigel basement extract). $500 \mu 1$ of media were added in the bottom wells. After $24 \mathrm{~h}$ of $\mathrm{CO}_{2}$ incubation at $37^{\circ} \mathrm{C}$, the non-invasive cells on the upper surface were removed and the cells migrated to the lower surface were fixed in $500 \mu \mathrm{l}$ of Cell Dissociation Solution/Calcein-AM, incubated al $37^{\circ} \mathrm{C}$ in $\mathrm{CO}_{2}$ incubator for $1 \mathrm{~h}$ and quantified by fluorimetric analysis.

\section{Western blot analysis}

Total cellular protein in three different treatments was isolated by the addition of $1 \%$ PMSF and RIPA lysis buffer (50mM Tris-HCl (pH7.4), 150m MNaCl, 1\%NP-40, 0.1\% SDS). After boiled with SDS-PAGE sample buffer for 5min, the samples were performed for sodium dodecylsulfate-polyacrylamide gel electrophoresis. Then the proteins were transferred onto a polyvinylidene difluoride membrane (Millipore, USA). After being blocked for $1 \mathrm{~h}$ at room temperature, the membrane was incubated with a 1:1000 dilution of rabbit polyclonal anti-mouse 
ET-1, $\beta$-catenin, E-cadherin, RhoA and RhoC and GAPDH (ABGENT, USA) overnight. Before detected with an ECL chemiluminescence detection kit (Advansta, USA), proteins were incubated with the corresponding secondary antibody for $1 \mathrm{~h}$ at room temperature. The bands were obtained by GeneGnome 5 (Synoptics Ltd., UK).

\section{Statistical analyses}

All data were calculated by mean \pm SD (standard deviation) and compared using ANOVA. The T test was used for comparisons. Statistical significance was assumed as $\mathrm{p}<0.05$. All statistical analyses were performed using the SPSS 13.0 statistical software.

\section{RESULTS}

ET-1 was high expressed in PC3 cell lines

In order to investigate the conditions of ET-1 expressions in prostatic cancer cell lines, LNCap cell line, PC3 cell line and DU145 cell line were used to perform Western Blot analysis of ET-1, and GAPDH was employed as a control (Figure 1A). As shown in Figure 1, the ET-1 protein was detectable in all prostatic cancer cell lines. However, the highest expression level of ET-1 protein appears on PC3 cell line and LNCap cell line and the lowest expression level of ET-1 protein appears on DU145 cell line, indicating that ET-1 protein in PC3 cell and LNCap cell was high expressed. Moreover, protein expressions of ET-1 were confirmed by gray value analysis, which is similar with the previous results in three different prostatic cancer cell lines (Figure 1B). However, the ET-1 protein expression in LNCap cell line was significantly differences compared 
with the GAPDH, which is contradictory with the previous analysis. In summary, the highest protein expression level of ET-1appears on the PC3 cell line.

\section{Effect of ET-1 knockdown in PC3 cells}

To knockdown the expression of ET-1 gene in PC3 cells, we designed a siRNA against ET-1. The ET-1 siRNA was used to transfect PC3 cells, and Western Blotting analysis was performed to measure ET-1 expression. The results showed that ET-1 treated with siRNA can effectively decreased ET-1 expression (Figure 2A, 2B). Moreover, protein expressions of ET-1 in experimental group were significant difference compared with the Control group and Mock group, which was confirmed by gray value analysis (Figure 2B). Therefore, ET-1 treated with siRNA were used in all subsequent experiments.

\section{Influence of treatments with ET-1 knockdown on PC3 cell proliferation}

To test whether ET-1 knockdown might affect PC3 cell proliferation, we introduced three treatments of Control, SiNC and SiRNA and observed the conditions of cell proliferation in Oh, 12h, 24h and 48h (Figure 3), respectively. There were no significant differences of cell proliferation between the three different treatments in $0 \mathrm{~h}, 12 \mathrm{~h}$ and $24 \mathrm{~h}$. Of the group in $48 \mathrm{~h}$, siRNA treatments were significant differences of cell proliferation compared with the control group and siNC group. However, there was no significant difference between siNC treatments and Control group. The results mentioned above suggested that ET-1 knockdown treatments on PC3 cells can effectively repress the cell proliferation.

\section{Effect of ET-1 knockdown treatment on cell cycle regulation and apoptosis in PC3 cell}

The effects of ET-1 knockdown treatmets on PC3 cell cycle and apoptosis were analyzed by flow cytometry. The results of Fluorescence Activated Cell Sorter (FACS) indicated that ET-1 
knockdown treatments on PC3 cells induced a transient cell accumulation in G1 and G2 phase (Figure 4A), while ET-1 knockdown treatments resulted in accumulation of cells in G1 phase, which was coincident with the cell decrease in G1 phase up to $48 \mathrm{~h}$ of transfection (Figure 3), suggesting a block at G1/G2 check point. Cell proliferation of ET-1 knockdown in PC3 cells was significantly refrained compared with the Mock and Control groups up to $48 \mathrm{~h}$. The results mentioned above suggested that ET-1 knockdown on PC3 cells can effectively repress the cell proliferation by preventing the cell cycling of G1/G2 phase. Moreover, ET-1 treated with siRNA resulted in a significant increase in apoptosis compared with Control and Mock groups, which indicated that ET-1 knockdown significantly promoted apoptosis (Figure 4B).

\section{Influence of treatments with ET-1 knockdown on PC3 cell invasion}

In order to investigate the invasion effect of ET-1 knockdown on PC3 cells, we used transwell chambers to assess the in vitro invasion potential of the tumor cells. Of the cell invasion analysis, the number of invasion cells in siRNA treated group was about half of control group and Mock group, and the number of invasion cell of siRNA treated was significantly decreased compared with control group and Mock group (Figure 5). The results mentioned above indicated that ET-1 knockdown treatment can effectively repress the cell invasion.

\section{Western blot analysis of biomarkers related with invasion and migration of PC3 cell}

The expressions of biomarkers related with invasion and migration, Including $\beta$-catenin, Ecadherin, RhoA and RhoC, were examined by Western Blot, respectively. GAPDH served as the loading control. Western blot analysis showed that ET-1 knockdown treatment caused a significant down-regulated protein expression of the RhoA (Figure 6) compared with Control group and Mock group. Meanwhile, the protein expressions of the other three markers ( $\beta$-catenin, E-cadherin and RhoC ) were significant up-regulated in ET-1 knockdown treatment compared 
with Control group and Mock group. Moreover, there is none of influence on the expressions of $\beta$-catenin, E-cadherin, RhoA and RhoC in the Control group and Mock group. However, ET-1 knockdown treatment could lead to the significantly down-regulated of the expression of RhoA and up-regulated of the expression of $\beta$-catenin, E-cadherin, RhoC.

\section{DISCUSSION}

Endothelin-1 (ET-1) is first isolated from porcine endothelial cells.ET-1 is about 10 times more potent that antiotensin II on a molar basis, which suggests that ET-1 has prolonged effects [14]. The endothelin family have several members with 21-amino acid, and those members are all characterized by two defining disulphide bridges (35). These members contains ET-1, ET-2 and ET-3, and the sarafotoxins (isolated from the venom of the Israeli burrowing asp Atractaspis engaddensis) (36-37). These ligands can bind to the ET receptors, with different affinity (38). The previous studies have proved ETs in all mammals and many higher vertebrates are identical. Endothelin-1 is generated by many different types of cells (23). The expression pattern of ET-1 is different to other neuroendocrine bioactive peptides. For example, the concentrations of immunoreactive ET-1 in seminal fluid areabout 500 times greater than the concentration in circulation (39). Previous studies have shown that Endothelin-1 can be detected in prostatic tissues in vivo (40) and prostate cells (41). Meanwhile, ET-1 can promote the proliferative effects of other peptide growth factors in certain prostate cancer cell lines (31). ET-1 can induce rapid tyrosine phosphorylation of EGFR in Rat-1 cells with absence of EGFR itself (42). Moreover, Endothelin-1can enhence intracellular calcium in several prostate cancer cell lines (43). Benign prostatic epithelium expresses the $\mathrm{ET}_{\mathrm{B}}$ receptor (44), but the $\mathrm{ET}_{\mathrm{B}}$ receptor is not expressed in 


\section{ET-1 Gene Effects on Prostate Cancer Cell}

prostate cancer cells. Based on the evidences mentioned above, inactivation of ET-1 in prostate cancer should be through the $\mathrm{ET}_{\mathrm{A}}$ receptor, as the $\mathrm{ET}_{\mathrm{B}}$ receptor is frequently "silenced". In order to gain understanding into the molecular events of ET-1 underlying the development of prostatic cancer, we analysis the protein expressions of ET-1 in PC-3 cell lines. Moreover, Effects of ET-1 knockdown in PC-3 cells were also performed. In the present study, Western Blot analysis clearly demonstrated that ET-1 knockdown in PC-3 cells can make the cell cycle distribution be retained in G1/G2 phase and cell proliferation was significantly refrained compared with the Mock and Control groups up to $48 \mathrm{~h}$. Meanwhile, ET-1 siRNA resulted in a significant increase in apoptosis compared with Control and Mock groups; ET-1 knockdown significantly promoted apoptosis. In addition, the invasion analysis by Boyden chamber showed that ET-1 knockdown reduced cell invasiveness up to $24 \mathrm{~h}$, which were confirmed by the western blot of biomarkers related with cell invasion. The protein expressions of biomarkers showed that ET-1 knockdown treatment caused a significant down-regulated protein expression of the RhoA compared with Control group and Mock group. Meanwhile, the protein expressions of the other three markers (beta-catenin, E-cadherin and RhoC) were significant up-regulated in ET-1 knockdown treatment compared with Control group and Mock group. Moreover, there is none of influence on the expressions of beta-catenin, E-cadherin, RhoA and RhoC in the Control group and Mock group. However, ET-1 knockdown treatment could result in significantly down-regulated expression of RhoA and up-regulated expression of beta-catenin, E-cadherin, RhoC. In the present study, we investigated the regulation of ET-1 knockdown treatment in PC-3 cell line, and the potential mechanismsin human prostate cancer cell line. Characterization of ET-1 in the development of tumors should lead to a better understanding in primary human prostate cancer. 


\section{REFERENCES}

1. Denmeade S, Lin X, and Isaacs J. Role of programmed (apoptotic) cell death during the progression and therapy for prostate cancer. Prostate 1996; 28:251-265.

2. Siegel RL, Miller KD, Jemal A. Cancer statistics, 2016. CA Cancer J Clin 2016; 66(1):730.

3. Ding L, Getz G, Wheeler DA, et al. Somatic mutations affect key pathways in lung adenocarcinoma. Nature 2008; 455: 1069-1075.

4. Jones S, Zhang X, Parsons, DW et al. Core signaling pathways in human pancreatic cancers revealed by global genomic analyses. Science 2008; 321: 1801-1806.

5. Parsons DW, Jones S, Zhang X, et al. An integrated genomic analysis of human glioblastoma multiforme. Science 2008; 321: 1807-12.

6. Kim, JH, Dhanasekaran, SM, Mehra R, et al. Integrative analysis of genomic aberrations associated with prostate cancer progression. Cancer Res 2007; 67: 8229-39.

7. Lapointe J, Li C, Higgins JP, et al. Gene expression profiling identifies clinically relevant subtypes of prostate cancer. Proc Natl Acad Sci USA 2004; 101: 811-16.

8. Lieberfarb ME, Lin M, Lechpammer M, et al. Genome-wide loss of heterozygosity analysis from laser capture microdissected pros-tate cancer using single nucleotide polymorphic allele (SNP) arrays and a novel bioinformatics platform dChipSNP. Cancer Res 2003; 63: 4781-5.

9. Paik S, Shak S, Tang G, et al. A multigene assay to predict recurrence of tamoxifentreated, node-negative breast cancer N Engl J Med 2004; 351: 2817-26.

10. Van de Vijver, MJ He, YD, van't Veer LJ, et al. A gene-expression signature as a predictor of survival in breast cancer. N Engl J Med 2002; 347: 1999-2009. 
11. Febbo PG and Sellers WR. Use of expression analysis to predict outcome after radical prostatectomy J Urol 2003; 170 (6 Pt 2): S11-9; discussion S19-20.

12. Singh D, Febbo PG, Ross K, et al. Gene expression correlates of clinical prostate cancer behavior. Cancer Cell 2002; 1: 203-9.

13. Patel JC, Maughan BL, Agarwal AM, et al. Emerging molecularly targeted therapies in castration refractory prostate cancer. Prostate Cancer 2013; 2013: 981684.

14. Yanagisawa M, Kurihara M, Kimura S, et al. A novel potent vasoconstrictor peptide produced by vascular endothelial cells. Nature (London).1988; 332: 411-15.

15. $\mathrm{Xu} \mathrm{D,} \mathrm{Emoto} \mathrm{N,} \mathrm{Giaid} \mathrm{A,} \mathrm{et} \mathrm{al.} \mathrm{ECE-1:} \mathrm{a} \mathrm{membrane} \mathrm{bound} \mathrm{metalloprotease} \mathrm{that}$ catalyses the proteolytic activation of big endothelin-1. Cell 1994; 78: 473-85.

16. Rubin SA, Levin ER. The endocrinology of vasoactive pep-tides: synthesis to function. J Clin Endocr Metabol 1994; 78: 6-10.

17. Burkhardt M, Barton M \& Shaw SG. Receptor- and non-receptor-mediated clearance of big-endothelin and endothelin-1: differential effects of acute and chronic $\mathrm{ET}_{\mathrm{A}}$ receptor blockade. J Hypertension 2000; 18: 273-9.

18. Bremnes T, Paasche JD, Mehlum A, et al. Regulation and intracellular trafficking pathways of the endothelin receptors. J Biol Chem 2000; 275:17596-604.

19. Battistini B, D’Orleans-Juste P, Sirois P. Endothelins: circulating plasma levels and presence in other biologic fluids. Lab Invest 1993; 68: 600-28.

20. Le Brun G, Aubin P, Soliman H, et al. Upregulation of endothelin 1 and its precursor by IL-1 $\beta$, TNF- $\alpha$, and TCG- $\beta$ in the PC3 human prostate cancer cell line. Cyto 1999; 11: $157-162$. 
21. Lees DM, Pallikaros Z, Corder R. The p55 tumor necrosis factor receptor (CD120a) induces endothelin-1 synthesis in endothelial and epithelial cells. Eur J Pharmacol 2000; 390: 89-94.

22. Goldie RG. Endothelins in health and disease: an overview. Clin Exp Pharmacol Physiol 1999; 26: $145-8$.

23. Rubanyi GM, Polokoff MA. Endothelins: molecular biology, biochemistry, pharmacology, physiology and patho-physiology. Pharmacol Rev 1994; 46: 328.

24. Mortensen LH. Endothelin and the clinical and peripheral nervous systems: a decade of endothelin research Clin Exp Pharmacol Physiol 1999; 26: 980-4.

25. Chiao JW, Moonga BS, Yang YM, et al. Endothelin-1 from pro-state cancer cells is enhanced by bone contact which blocks osteoclastic bone resorption. Br J Cancer 2000; 83: $360-5$.

26. Sullivan ME, Mumtaz FH, Khan MA, et al. Endothelins in the urinary tract. Br J Urology 2000; 86:97-106.

27. Levy A, Levy N, Wegner S. Transcriptional regulation of the rat vascular endothelial growth factor gene by hypoxia. J Biol Chem 1995; 270: 333-400.

28. Masaki T, Miwa S, Sawamura T, et al. Subcellular mechanisms of endothelin action in vascular system. Euro J Pharmacol. 1999; 375: 133-8.

29. Nelson JB and Carducci M. The role of the endothelin axis in prostate cancer. Prostate J 1999; 1:126-30.

30. Nelson JB, Chan-Tack K, Hedican SP, et al. Endothelin-1 production and decreased endothelin B receptor expression in advanced prostate cancer. Cancer Res 1996; 56: 6638. 
31. Nelson JB, Hedican S, George D, et al. Identification of endothelin-1 in the pathophysiology of metastatic adenocarcinoma of the prostate. Nat Med 1995; 1: 944-9.

32. Nelson J, Chan-Tack K, Hedican S, et al. Endothelin-1 production and decreased ET B receptor expression in advanced prostate cancer. Cancer Res 1996; 56: 663-8.

33. Nelson JB, Lee WH, Nguyen SH, et al. Methylation of the 5' CpG island of the endothelin B receptor gene is common in human prostate cancer. Cancer Res 1997; 57: $35-7$.

34. Wu-Wong JR, Chiou WJ, Dickinson R, and Opgenorth TJ. Endothelin attenuates apoptosis in human $\quad$ smooth muscle cells. Biochem J 1997; 328: 733-7.

35. Inoue A, Yanagisawa M, Kimura S, et al. The human endothelin family: three structurally and pharmacologically distinct isopeptides predicted by three separate genes. Proc Natl Acad Sci USA 1989; 86: 2863-7.

36. Kochva E, Viljoen CC, Botes DP. A new type of toxin in the venom of snakes of the genusAtractaspis (Atractaspidinae). Toxicon 1982; 20: 581-92.

37. Kochva E, Bdolah A, Wollberg Z. Sarafotoxins and endothelins: evolution, structure and function. Toxicon 1993; 31: 541-68.

38. Huggins SP, Pelton JT, Miller RC. The structure and specificity of endothelin receptors: their importance in physiology and medicine. Pharmac Ther 1993; 59: 55-123.

39. Casey ML, Byrd W, MacDonald PC. Massive amounts of immunoreactive endothelin in human seminal fluid. J Clin Endocrinol Metabol 1992; 74: 223-5.

40. Langenstroer P, Tang R, Shapiro Eet al. Endothelin-1 in the human prostate: tissue levels, source of production and isometric tension studies. J Urol 1993; 149: 495-9. 
41. Walden PD, Ittmann M, Monaco ME, et al. Endothelin-1 production and agonist activities in cultured prostate-derived cells: implications for regulation of endothelin bioactivity and bioavailability in prostatic hyperplasia. Prostate 1998;

34: 241 .

42. Daub H, Weiss FU, Wallasch Cet al. (1996) Role of transactivation of the EGF receptor in signaling by G-protein-coupled receptors. Nature 379: 557-60.

43. Wasilenko WJ, Cooper J, Palad AJ, et al. Calcium signaling in prostate cancer cells: evidence for multiple receptors and enhanced sensitivity to bombesin/GRP. Prostate 1997; 30: 167-73.

44. Kobayashi S, Tang R, Wang B, et al. Localization of endothelin receptors in the human prostate. J Urol 1994; 151: 763-6. 


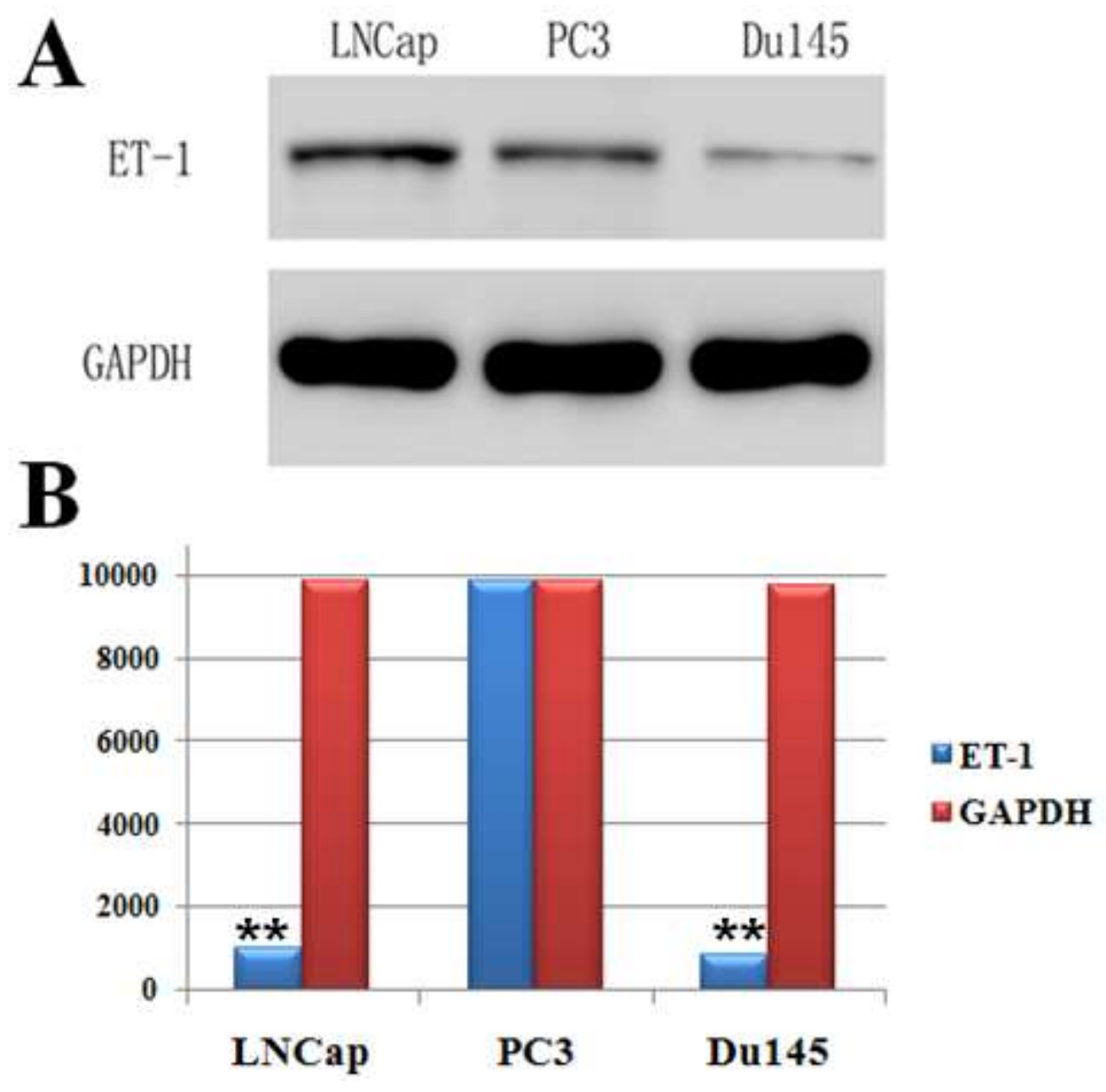

Fig.1: Western Blot analysis of ET-1 protein expression in LNCap cell line, PC3 cell line and DU145 cell line.

* represents the significant different compared with the control ( $\mathrm{P}<0.05$, T-test). 


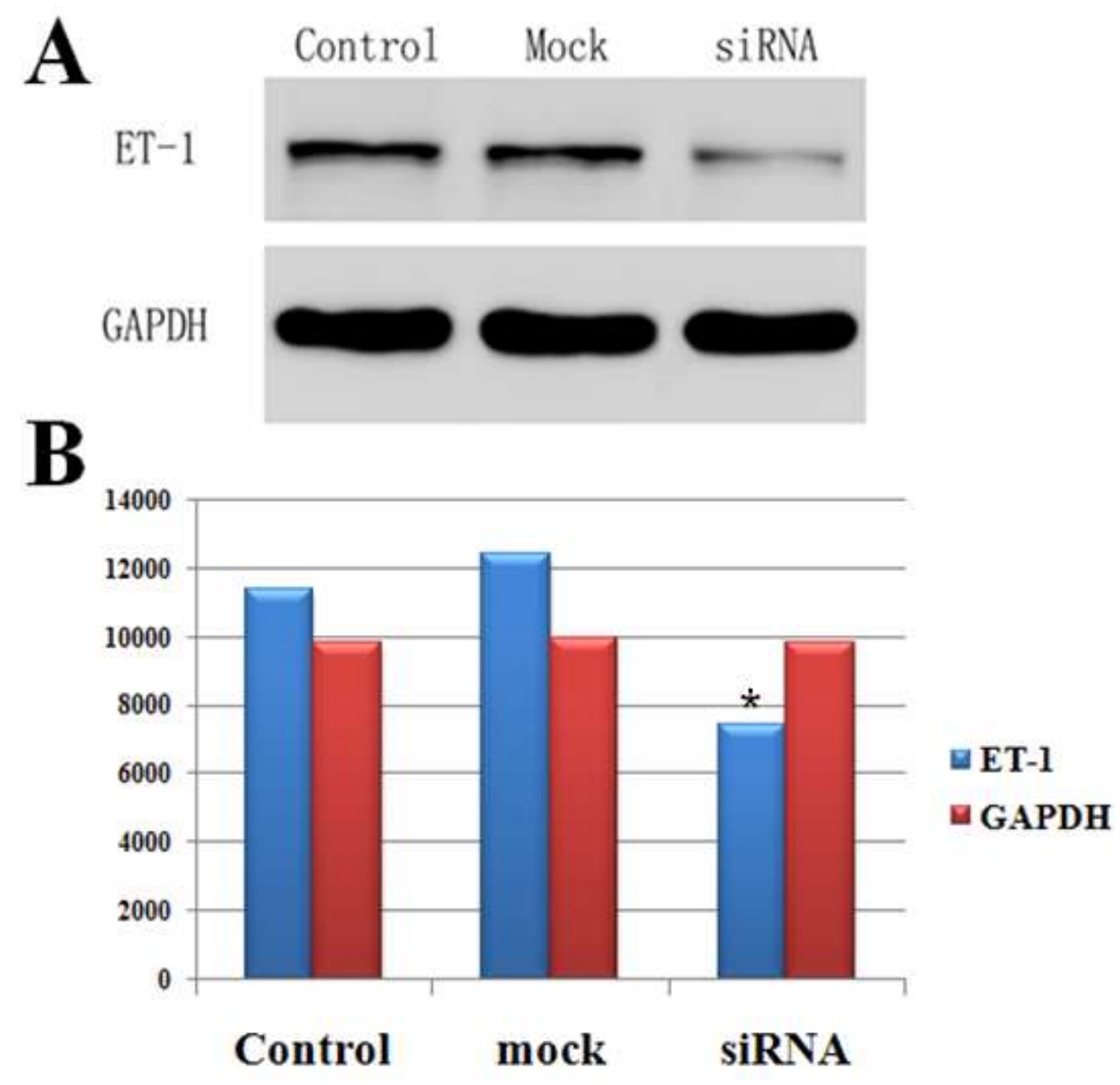

Fig.2: Western Blot analysis of ET-1 expression in ET-1 knockdown, Control and Mock treatments in PC3 cell line.

* represents the significant different compared with the control $(\mathrm{P}<0.05, \mathrm{~T}$-test $)$.

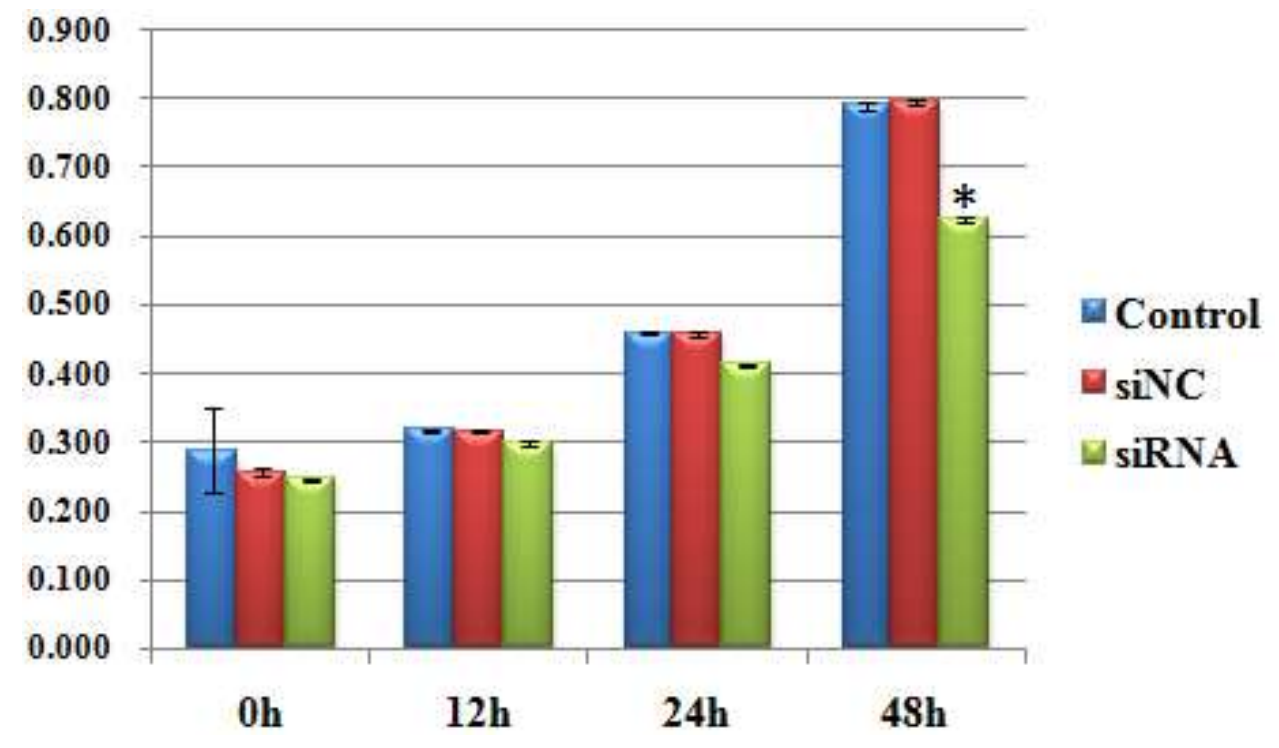


Fig.3: Cell proliferation of ET-1 knockdown in PC3 cell line.

Control: normal PC3 cells, SiNC: mock-vehicle of PC3 cells, siRNA: ET-1 knockdown of PC3 cells. CCK 8 method examines the cell proliferation of three different treatments in $6 \mathrm{~h}, 12 \mathrm{~h} 24 \mathrm{~h}$, and $48 \mathrm{~h}$. The vertical axis represents the optical density value (OD).* represents the significant different compared with the control $(\mathrm{P}<0.05$, T-test).
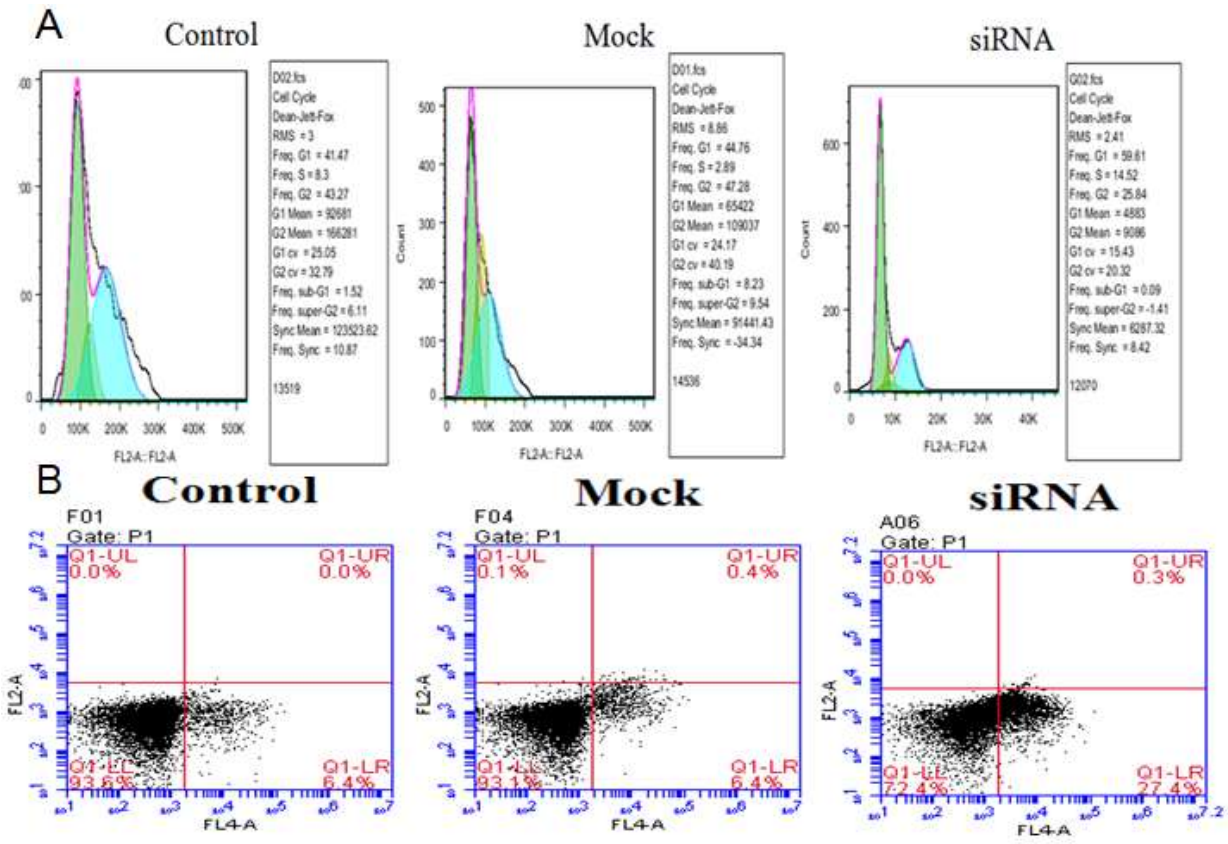

Fig.4: The effects of ET-1 knockdown on cell cycle and apoptosis in PC3 cell line.

Flow cytometry checks the cell cycle of PC3 with three different treatments up to 24h. Apoptosis was assessed using the Annexin V-FITC Apoptosis Detection Kit. 
Liu et al

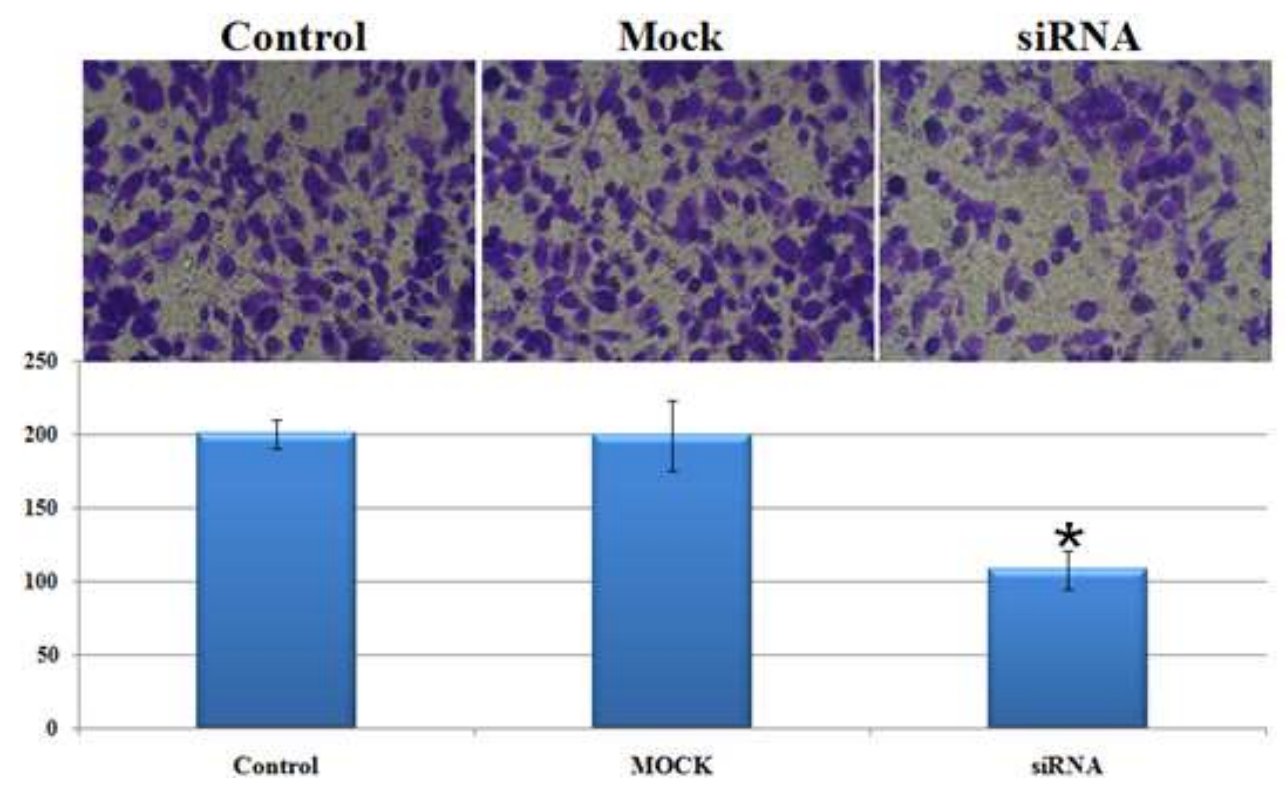

Fig.5: ET-1 knockdown in PC3 cell line reduces invasion.

PC3 cells treated with ET-1 knockdown were seeded in the upper chamber of transwell filters. After $24 \mathrm{~h}$ incubation, the top of the filters were scraped and cells that Matrigel-invaded through the filters were fixed and stained. Images are representative of invaded cells of one field. 

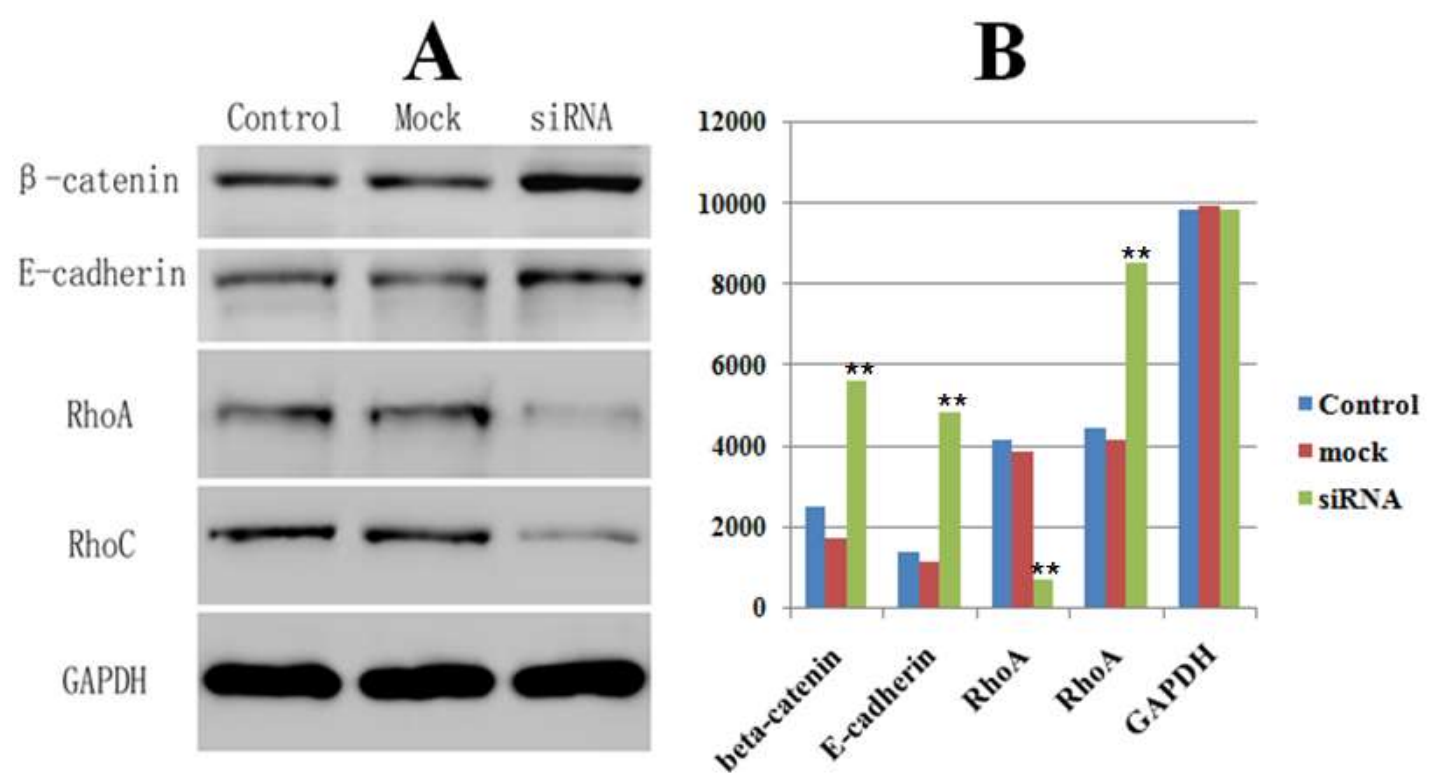

Fig.6: Western Blot analysis of invasion related genes with ET-1 knockdown treatments in PC3 cells Control: normal PC3 cells, Mock: mock-vehicle of PC3 cells, siRNA: ET-1 knockdown of PC3 cells. $* * \mathrm{P}<0.01$. 